$07 ; 15$

\title{
Импульсная активация топливного элемента на основе протонпроводящей полимерной мембраны
}

() Е.А. Галицкая ${ }^{1,2}$, Е.В. Герасимова ${ }^{2}$, Ю.А. Добровольский ${ }^{2}$, Г.М. Дон ${ }^{3}$, А.С. Афранасьев ${ }^{4}$, А.В. Левченко ${ }^{2}$,

А.В. Сивак ${ }^{3}$, В.В. Синицын ${ }^{1,2, \text { Ф }}$

${ }^{1}$ Институт фризики твердого тела РАН, Черноголовка, Московская обл., Россия

${ }^{2}$ Институт проблем химической фризики РАН, Черноголовка, Московская обл., Россия

${ }^{3}$ ООО „Инэнерджи“, Москва, Россия

${ }^{4}$ Филиал 46 Центрального научно-исследовательского института

Министерства обороны РФ, Мытищи, Московская обл., Россия

『 E-mail: sinitsyn@issp.ac.ru

Поступило в Редакцию 13 октября 2017 г.

Проведены исследования влияния импульсной активации на электрохимические характеристики топливных элементов на основе протонпроводящей мембраны Nafion. Активация представляла собой многократно повторяющийся импульсный режим работы мембранно-электродного блока (МЭБ), который характеризовался чередованием постоянной нагрузки МЭБ вблизи тока короткого замыкания при напряжении $U_{L}=0.1 \mathrm{~V}$ и его „простоя“, соответствующего напряжению разомкнутой цепи МЭБ $U_{\mathrm{OCV}} \approx 0.95 \mathrm{~V}$. Показано, что имеется оптимальное соотношение временны́х параметров импульсной нагрузки, при которых активация идет намного эффективнее, чем в случае постоянного потенциостатического или гальваностатического режимов, часто используемых на практике.

DOI: $10.21883 /$ PJTF.2018.13.46325.17078

При создании водородно-воздушных топливных элементов (ВВТЭ) на основе протонпроводящих полимерных мембран в целях достижения их наилучшей производительности и стабильной работы необходимо проводить процедуры активации вновь созданных ВВТЭ [1-10]. Такие процедуры применяются и для единичных топливных элементов - 


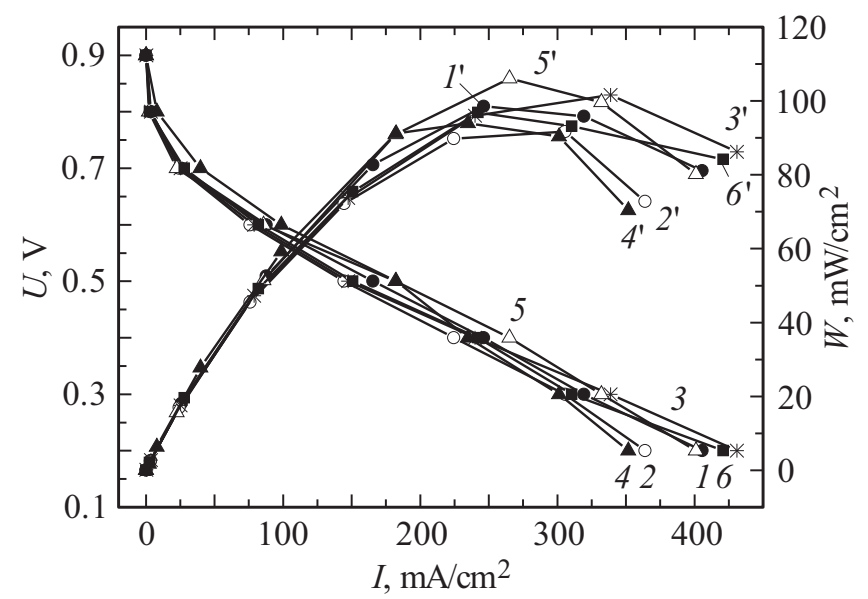

Рис. 1. Поляризационные кривые $(1-6)$ и мощностные характеристики $\left(1^{\prime}-6^{\prime}\right)$ исходных МЭБ до активации. Номера кривых соответствуют номерам образцов.

так называемых мембранно-электродных блоков (МЭБ), и для батарей, представляющих собой сборку последовательно соединенных МЭБ. Наибольшее распространение среди исследователей и производителей ВВТЭ получил потенциостатический тип активации отдельных МЭБ при постоянном напряжении топливного элемента $U_{L}=0.5-0.6 \mathrm{~V}$ (напряжение, выдаваемое топливным элементом на внешнюю нагрузку) [2,7-9]. В этом случае при корректной сборке МЭБ наблюдается монотонный рост тока с выходом на стационарные значения, и это время выхода принимается за время активации (в англоязычной литературе эта процедура носит название „,break-in“), необходимой для получения требуемой производительности нового ВВТЭ. Наряду с таким достаточно простым методом активации предлагаются и более сложные пути достижения требуемой производительности МЭБ, включающие в себя поэтапное варьирование по току нагрузки $[2,6]$, потенциалу нагрузки $[2,7,8]$, составу газа $[2,5]$ и температуре $[2,9]$. При этом используется как отдельное воздействие на МЭБ по каждому из перечисленных параметров, так и комплексное, суммарная продолжительность таких процедур, как правило, составляет несколько часов $[2,3,9]$.

Письма в ЖТФ, 2018, том 44, вып. 13 


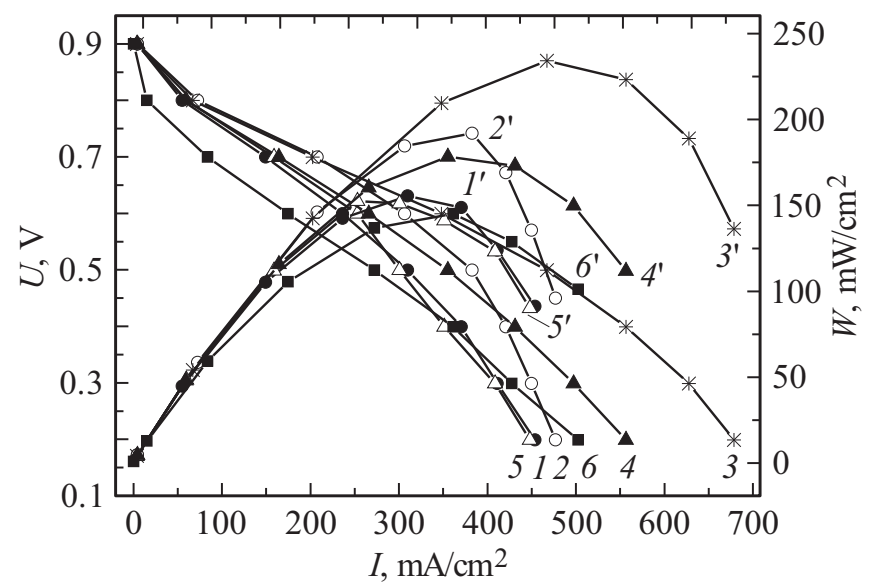

Рис. 2. Поляризационные кривые $(1-6)$ и мощностные характеристики $\left(1^{\prime}-6^{\prime}\right)$ МЭБ при различных временах нагрузки $\tau_{2}$ в условиях постоянной величины времени релаксации $\tau_{1}=20 \mathrm{~s}$. $\tau_{2}, \mathrm{~s}: 1,1^{\prime}-5,2,2^{\prime}-20,3,3^{\prime}-40,4,4^{\prime}-60$, $5,5^{\prime}-80,6,6^{\prime}-$ стационарный режим $3 \mathrm{~h}$, нагрузка $500 \mathrm{mV}$. Номера образцов соответствуют рис. 1 .

Следует отметить, что используемые в литературе параметры активации в основном соответствуют потенциостатическим или гальваностатическим режимам нагрузки при токах ниже максимума мощности (мощностная характеристика ВВТЭ как функция тока имеет максимум, см., например, рис. 1,2). Это связано с опасениями значительно снизить ресурсное время работы МЭБ при больших плотностях тока, соответствующих напряжениям топливного элемента $U_{L} \leqslant 0.3 \mathrm{~V}$, приводящих к его деградации.

С другой стороны, в работах $[2,11]$ было установлено, что небольшая по продолжительности активация МЭБ токами короткого замыкания может восстановить рабочие характеристики уже активированного топливного элемента, причем данную процедуру использует ряд производителей для своих коммерческих продуктов. В связи с этим возникал вопрос: в какой степени импульсная активация токами большой плотности в области малых напряжений топливного элемента $\left(U_{L} \leqslant 0.1 \mathrm{~V}\right)$ может оказаться эффективнее по времени, чем часто используемая в

Письма в ЖТФ, 2018, том 44, вып. 13 
настоящее время потенциостатическая активация до максимума снимаемой мощности? Кроме того, оптимизация этой процедуры (в первую очередь по времени) имеет важное значение с производственной точки зрения, так как она является неотъемлемой составляющей процесса изготовления топливного элемента.

Для выяснения этого вопроса нами были проведены целенаправленные исследования по определению оптимальных параметров импульсного воздействия токов на электрохимические характеристики МЭБ. В настоящей работе были исследованы следующие импульсные режимы активации $\left(\tau_{1}-\right.$ время простоя МЭБ при напряжении разомкнутой цепи $U_{\mathrm{OCV}}, \tau_{2}$ - время нагрузки при напряжении ячейки $\left.U_{L}=0.1 \mathrm{~V}\right)$ : 1) $\tau_{1}=20 \mathrm{~s} ; \tau_{2}=5,20,40,60$ и $80 \mathrm{~s}$ (меняется время нагрузки, время простоя постоянное);

2) $\tau_{1}=40 \mathrm{~s} ; \tau_{2}=5,20,40,60$ и $80 \mathrm{~s}$ (также меняется только время нагрузки, а время простоя постоянное и в 2 раза больше, чем в предыдущем случае).

Диапазон изменения времени воздействия $\tau_{2}$ выбирался согласно данным работ $[2,11]$, где активация током короткого замыкания в течение $30 \mathrm{~s}$ приводила к существенному улучшению мощностных характеристик МЭБ. Для оценки времени релаксации принималось, что релаксация обусловлена диффузионными процессами миграции протонов в МЭБ. Характерная толщина составляющих элемента „мембрана + каталитический слой,, (где и возникают неравновесные носители тока при активации) составляет $\sim 70 \mu \mathrm{m}$, а коэффициент самодиффузии протонов в Nafion (протонпроводящая мембрана на основе перфторированного полимера с сульфокислотными группами) $\sim 10^{-6}-10^{-5} \mathrm{~cm}^{2} / \mathrm{s}[12,13]$, что, согласно выражению

$$
\tau_{1}=l^{2} / 6 D
$$

( $l-$ расстояние, $D-$ коэффициент диффузии), дает $\tau_{1} \sim 1-10 \mathrm{~s}$. Выбранные нами значения $\tau_{1}$ были несколько выше сделанной оценки и для выяснения роли времени релаксации было задействовано два режима, в которых величина $\tau_{1}$ различается в 2 раза.

Исследования проводились на идентичных МЭБ на основе мембраны Nafion 212 (DuPont) и газодиффузионных слоев (ГДС) Freudenberg I2C8 (Freudenberg FCCT SE\&Co KG). В качестве электродов использовался композит иономер Nafion-Pt/C-катализатор, который напылялся

Письма в ЖТФ, 2018, том 44, вып. 13 
на поверхность ГДС площадью $1 \mathrm{~cm}^{2}$ с загрузкой по платине $0.4 \mathrm{mg} / \mathrm{cm}^{2}$ с помощью установки Prism BT (Ultrasonic Systems, Inc.). Состав высокодисперсного платино-углеродного катализатора для анода и катода был идентичным. В настоящей работе использовался катализатор $\mathrm{Pt} / \mathrm{C}$ производства ООО „Инэнерджи“ $[14,15]$, содержащий $29 \% \mathrm{Pt}$ на углеродном носителе. МЭБ изготавливались путем горячего прессования мембраны между двумя ГДС при температуре $130^{\circ} \mathrm{C}$ и давлении $80 \mathrm{~kg} / \mathrm{cm}^{2}$ в течение $3 \mathrm{~min}$.

Процедуры активации МЭБ проводились на стенде G-60 Test Station (Greenlight Innovation Corp.) при комнатной температуре и в условиях 100\% увлажнения газов. В качестве топлива использовался чистый водород, в качестве окислителя - воздух. Электрохимические измерения осуществлялись в ячейке Elecrtochem (Electrochem, Inc.). Поляризационные зависимости ток-напряжение и импедансные спектры измерялись на потенциостате-гальваностате Elins P-40X с модулем измерения электрохимического импеданса FRA-24M.

Имеющиеся в литературе данные свидетельствуют о том, что наиболее активно процесс активации ВВТЭ протекает в первые 2-3 h [1-6], поэтому полным временем импульсного воздействия для обоих режимов было выбрано $3 \mathrm{~h}$. Для выяснения особенностей изменения электрохимических характеристик МЭБ нами измерялись поляризационные кривые всех исследуемых образцов до и после испытаний.

На рис. 1 приведены поляризационные $(U-I)$ и мощностные $(W-I)$ характеристики исходных образцов. Видно, что для всех исследованных образцов зависимости $U-I$ и $W-I$ близки между собой, что соответствует хорошей воспроизводимости получения МЭБ используемым в работе методом. На поляризационных кривых образцов до их активации можно выделить два участка: сильно нелинейный участок при токах менее $30 \mathrm{~mA} / \mathrm{cm}^{2}$, когда наблюдаемое перенапряжение связано с низкой скоростью электрохимических реакций на электродах (активационные потери), и участок, близкий к линейному при токах более $50 \mathrm{~mA} / \mathrm{cm}^{2}$, где вклад в перенапряжение обусловлен омическим сопротивлением топливного элемента. Образцы до активации характеризуются невысокими значениями мощности с максимальной величиной вблизи $95 \pm 5 \mathrm{~mW} / \mathrm{cm}^{2}$ (рис. 1 ).

После активации (рис. 2) с фиксированным значением времени релаксации $\tau_{1}=20 \mathrm{~s}$ и различными значениями времени нагрузки $\tau_{2}$ вид зависимостей $U-I$ и $W-I$ существенно меняется: снимаемая с МЭБ

Письма в ЖТФ, 2018, том 44, вып. 13 


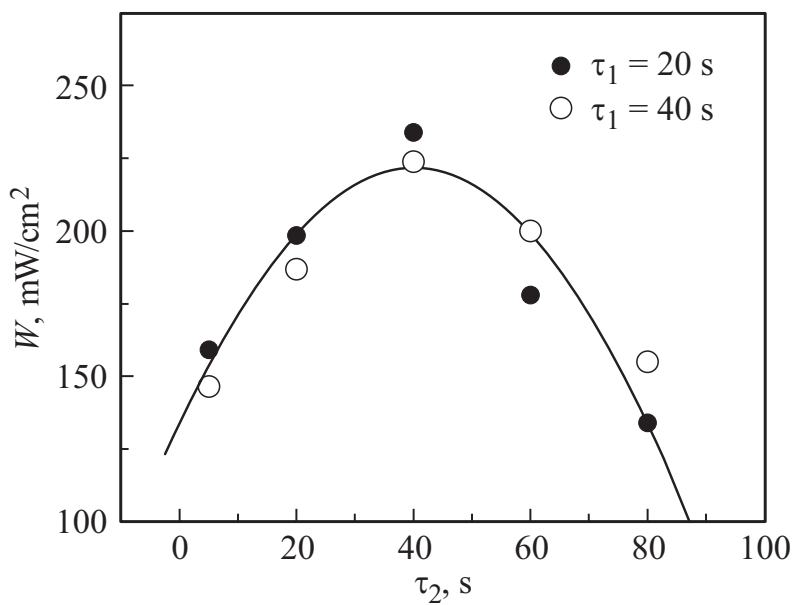

Рис. 3. Значения максимума снимаемой мощности $W$ образцов после импульсного воздействия в зависимости от периода нагрузки $\tau_{2}$ при периодах релаксации $\tau_{1}=20$ и $40 \mathrm{~s}$.

мощность значительно возрастает; на поляризационных кривых $U-I$ появляется еще один нелинейный участок при токах выше $\sim 500 \mathrm{~mA} / \mathrm{cm}^{2}$, отвечающий диффузионным ограничениям (потери вследствие массопереноса).

На рис. 3 показана зависимость максимального значения снимаемой мощности от времени нагрузки. Видно, что максимальное значение мощности, достигнутое после активации МЭБ, отвечает времени нагрузки 40s (образец № 3). В этом случае по сравнению со значением для исходного образца мощность увеличилась почти в 1.5 раза и составила $W=234 \mathrm{~mW} / \mathrm{cm}^{2}$. Наряду с импульсной активацией в работе была также проведена стандартная активация в потенциостатическом режиме при $U_{L}=0.5 \mathrm{~V}$ в течение $3 \mathrm{~h}$ (на рис. 1 и 2 это кривые 6 и $6^{\prime}$ ). Видно, что значения снимаемой мощности в этом случае существенно ниже, чем для образца № 3 с оптимальными параметрами импульсной активации. Следует отметить, что при значительном увеличении времени воздействия (до $10 \mathrm{~h}$ ) в данном потенциостатическом режиме значения снимаемой мощности приближались к характеристикам образца № 3. Улучшение мощностных характеристик с увеличением

Письма в ЖТФ, 2018, том 44, вып. 13 
времени воздействия также наблюдалось и для образцов № 1 и 2 , для которых период нагрузки $\tau_{2}$ был меньше, чем для образца № 3 . С другой стороны, для образцов № 4 и 5 с бо́льшим периодом нагрузки, чем в оптимальном случае, увеличение полного времени активации приводило к снижению снимаемой мощности, т.е. к деградации МЭБ. При этом важно отметить, что значения снимаемой мощности для образцов № 4 и 5 при времени воздействия, меньшем $3 \mathrm{~h}$, были ниже, чем для образца № 3. Также отметим, что увеличение периода релаксации в 2 раза не сказалось на величине оптимального значения периода нагрузки, т.е. времена релаксации больше $20 \mathrm{~s}$ не являются критическими при импульсной активации, однако требуют увеличения общего времени воздействия.

Таким образом, проведенные исследования позволяют сделать важный вывод: импульсное воздействие при высоких значениях поляризации ячейки (низких значениях напряжения, выдаваемого самой ячейкой под такой нагрузкой) существенно эффективнее, чем стационарные режимы активации в области поляризации ячейки до максимума мощности на зависимостях $W-I$, и использованный нами тип импульсного воздействия (меандр) при напряжении ячейки $U_{L}=0.1 \mathrm{~V}$ имеет оптимальный период нагрузки, равный $40 \mathrm{~s}$, для данной конфигурации МЭБ (тип мембраны и состав катализатора).

Работа выполнена в рамках проекта РНФ № 17-79-30054.

\section{Список литературы}

[1] Xu Zh., Qi Zh., He Ch., Kaufman A. // J. Power Sources. 2006. V. 156. N 2. P. 315-320.

[2] Yuan X.-Z., Zhang Sh., Sun J.C., Wang H. // J. Power Sources. 2011. V. 196. N 22. P. 9097-9106.

[3] Yuan X.-Z., Sun J.C., Wang H., Li H. // J. Power Sources. 2012. V. 205. P. 340 344.

[4] Murthy M., Sisofo III N.T., Baczowski C.A. Method and device to improve operation of a fuel cell. 2006. US2006/0166051 A1.

[5] He C., Qi Z., Hollett M., Kaufman A. // Electrochem. Solid-State Lett. 2002. V. 5. N 8. P. A181-A183.

[6] Bi W., Gray G.E., Fuller T.F. // Electrochem. Solid-State Lett. 2007. V. 10. N 5. P. B101-B104. 
[7] Lim T.W., Kim S.H., Ahn S.Y., Hong B.K., Ahn B.K. System and method for activating fuel cell. 2010. US 2010/0129689 Al.

[8] Weng F.-B., Jou B.-S., Su A., Chan S.H., Chi P.-H. // J. Power Sources. 2007. V. 171. N 1. P. 179-185.

[9] Bezmalinovi D., Rado J., Barbir F. // Acta Chim. Slov. 2015. V. 62. N 1. P. 8387.

[10] Кузов А.В., Тарасевич М.Р., Богдановская В.А., Модестов А.Д., Трипачев О.В., Корчагин О.В. // Электрохимия. 2016. Т. 52. № 7. С. 790-800.

[11] Xie Z., Zhao X., Adachi M., Ken S., Mashio T., Ohma A., Shinohara K., Holdcroft S., Navessin T. // Energy Environ. Sci. 2008. N 1. P. 184-193.

[12] Kreuer K.D., Schuster M., Obliers B., Diat O., Traub U., Fuchs A., Klock U., Paddison S.J., Maier J. // J. Power Sources. 2008. V. 178. N 2. P. 499-509.

[13] Zawodzinski T.P., Neeman M., Sillerud L.O., Gottesfeld S. // J. Phys. Chem. 1991. V. 95. N 15. P. 6040-6044.

[14] Заявка на патент ТУ 1794-005-89376778-2016 „Электрокатализатор“.

[15] Павлов В.И., Герасимова Е.В., Золотухина Е.В., Дон Г.М., Добровольский Ю.А., Ярославцев А.Б. // Рос. нанотехнологии. 2016. Т. 11. № 11-12. C. 43-49. 